Sādhanā Vol. 28, Part 5, October 2003, pp. 867-874. @ Printed in India

\title{
Twentieth Century evolution of machining in the United States - An interpretative review
}

\author{
M EUGENE MERCHANT \\ Techsolve, 1111 Edison Drive, Cincinnati, OH 45216, USA \\ e-mail: merchant@techsolve.org
}

\begin{abstract}
Although the machining process came into use in industry at the very beginning of the Industrial Revolution in the late 1700's, virtually no technologi$\mathrm{cal} /$ mathematical representations (i. e. 'models'), capable of describing the physics or mechanics of the machining process, came into being for over 200 years. Yet such models are essential to establishment of an engineering basis for determining proper machining parameters for obtaining predictable, high productivity in applying the machining process in practice. At last, during the 20th Century, such technology did begin to evolve, going through three main stages in that period, namely empirical modelling, science-based (predictive) modelling and computerbased modelling. Empirical modelling can be said to have had its beginning as an organized process in the late 1890s to early 1900s. Science-based modelling began to emerge in the 1940s and computer-based modelling in the 1970s. Each of these three stages was ushered in by a key event in America. The first originated with F W Taylor's pioneering engineering research and development of empirical methodology (and equations) for estimating reasonably economic machining conditions. The second stage was primarily initiated by Merchant's mechanics-based modelling and analysis of the basic force system that acts between cutting tool, chip and workpiece in a machining process. The third (and major) stage was the "watershed" event of the advent of digital computer technology and its application to manufacturing in general. That enabled integration of computer-based modelling with all of the databases of the full system of manufacturing.
\end{abstract}

Keywords. Manufacturing; machining process; empirical modelling; sciencebased modelling; computer-based modelling.

\section{Introduction}

This paper presents a brief overview, of an interpretive nature, of American contributions to the evolution of the technology of the modelling of machining during the 20th Century. Such technology is of very considerable importance to the manufacturing industry of the world, since machining is by far the most widely used machine-performed process in the manufacture of mechanical products in industrialised countries today. Its economic impact is tremendous.

A list of symbols is given at the end of the paper 
This is due to the fact that today, in industrialized countries, the cost of machining now amounts to more than 15 percent of the total value of all products made by their entire manufacturing industry, whether or not these products are mechanical.

Widespread performance of the process of the machining of metals came into being with the industrial application of that process that sprang from the advent of the Industrial Revolution in the late 1700's, in Britain. In fact, the prime catalyst of the advent of that Revolution was the development, by Wilkinson, in Britain in 1775, of the capability to bore a large cylinder to an accuracy equal to the thickness of a worn shilling. That made it possible for James Watt to actually produce the steam engine that he had earlier invented.

Initially, of course, machining was an art. No technological/mathematical representations, i.e. "models", existed that were capable of describing even the rudiments of the physics or mechanics of the machining process. Furthermore, and more importantly at that time, no technological models existed that could provide an engineering basis for determining proper machining parameters (such as cutting speed, feed rate and cutting tool characteristics) for obtaining predictable and high productivity in applying the machining process in practice. The only "models" present for the selection of such parameters were the non-technological "trial-and-error-based" ones developed by each individual machinist. As could be expected, this situation resulted in the average productivity of machining operations being quite low in practice. This was of no serious economic consequence at first. However, one would have expected that, by the middle of the 19th Century, as machine tools began to be manufactured in significant numbers and machining started to become one of industry's major manufacturing process, significant efforts would have been instituted to develop technological/physical models for engineering of efficient machining. Surprisingly enough, however, this did not really begin to evolve for almost another 40 years, with many of the important contributions to this evolution being made by researchers in America, as we shall see.

\section{Evolution of modelling technology}

In the 20th Century, technology for the modelling of machining finally began to evolve, going through three main stages of that period. These were as given below.

(1) Empirical modelling, beginning in (or just prior to) the early 1900s.

(2) Science-based (predictive) modelling, beginning in the 1940s.

(3) Computer-based modelling, beginning in the 1970s

Each of the stages was triggered by a key event and, interestingly enough, all three of these stages today co-exist and synergise each other. We will describe and interpret the main character of each of the three stages and discuss the key event that ushered in each of them.

\section{Empirical modelling}

The main characteristic of the modelling of machining driving this early stage is that it was limited to use of experimental data as the basis for its models. That meant, of course, that the models were not truly predictive. Instead they were limited to situations where the ranges of the parameters of the operation to be modelled closely mimicked those prevailing during the experiments from which the original data was derived.

The pioneering figure who stepped forward to institute successful empirical modelling of the machining process was F W Taylor. In 1880, he launched and then carried out a 
massive, wholly factory-based research programme at a company known as the Midvale Steel Works - a programme that lasted 26 years. The primary aim of his research, as stated by him, was to establish models that could answer three main questions asked by machinists, namely:

(1) What cutting speed shall I use?

(2) What feed shall I use?

(3) What cutting tool shall I use?

His research produced (in addition to much empirical understanding of machining operations) a whole series of empirical equations (models), suitable for use by machinists, in the form of slide rules. The best known and most widely used of these models was the equation:

$$
V T^{n}=C,
$$

where

$n=$ exponent whose value varies somewhat with machine and work material parameters,

$C=$ empirical constant whose value depends on the specific machine and work material parameters of the particular operation.

This model is still widely used today, even though no scientific basis for it appears to have been established yet.

Taylor kept the results of his research secret for 26 years, handling them as proprietary information that he licensed to clients or sponsoring manufacturing companies. Then, in 1906, he published the results of his research in his mammoth paper entitled "On the art of cutting metals". This he presented in his role as President of the American Society of Mechanical Engineers (ASME), as the President's Annual Address at the Society's 27th Annual Meeting in New York, on 4 December, 1906. It was printed in full in the Transactions of the Society (Taylor 1906). It comprises 248 printed pages, 24 huge foldouts containing tables and curves, and 64 pages of discussion, ending with the author's closure. Some 1,300 persons attended that meeting, requiring the use of the New York Edison Company's auditorium to accommodate the crowd of attendees. Thus the results of his massive research programme finally became generally available to the entire manufacturing industry. In the meantime, their application at Midvale, and at his licensed clients and sponsors, had resulted in an increase, on average, of $200-300 \%$ in the productivity of their machine tools and of $25-100 \%$ in the pay of their machinists!

As a result of the publication of Taylor's work, a strong effort to continue the development of a broad empirical basis for the technological modelling of the machining process gradually emerged, and then continued unabated through the 1940s. During all of the period from 1906 on, substantial progress was made, with a major part of that coming from the efforts of American engineering researchers and manufacturing engineers. In contrast with Taylor's work, the effort was no longer confined almost wholly to industry, but quickly spread to universities as well. Further, and in contrast with Taylor's work, the effort was marked by increasingly close cooperation between industry and academia. A substantial empirical understanding developed of how to model efficient and economic applications of the metal cutting process in practice. A sizable contingent of proficient researchers in this field evolved, in both academia and industry, with their "rallying point" eventually becoming the ASME Research Committee on the Cutting of Metals, organized in 1923. This contingent of researchers could be said to have been the "hard core" of the contributors to the development of this empirical 
understanding. Then, beginning in the 1940's, a new approach to the modelling of machining began to evolve, namely science-based modelling of such.

\section{Science-based modelling}

The basic characteristic of science-based modelling of machining is that it draws on the established natural sciences, and particularly the science of physics, to establish reliable predictive models. These are models that can then be used to carry out reliable engineering calculations of the expected behaviour or characteristics of a machining process, independent of empirical information.

Development of capability for science-based modelling of machining was quite dependent of the knowledge and understanding of machining developed by the research on empirical modelling. A good example of such was the research done by the Ernst-Merchant team at Cincinnati Milling Machine Company (now named Milacron) in the period from 1936 to 1957 which culminated in the creation by Merchant of the basic science-based model of the machining process. Hans Ernst was the company's Director of Research at that time.

Ernst was an inquisitive and imaginative inventor and researcher. Among other things, he was particularly curious about the mechanism by which a cutting tool removes metal from a workpiece, i.e. the process of chip formation. To investigate this, he had previously carried out such activities as studying the action of chip formation through the microscope during cutting and taking high-speed motion pictures of such. He also made photomicrographs of sections through chips still attached to workpieces (obtained by suddenly stopping a cut while in process). He published the findings of his research in a variety of technical papers, of which his classic paper titled "Physics of metal cutting", published in the book titled "Machining of metals" by the American Society for Metals (Ernst 1938), is typical. As a result of this type of empirical research, he arrived at the concept of the "shear plane" in chip formation, i.e. the very narrow plastic zone ("plane") between the body of the workpiece and the body of the chip that is being removed by the cutting tool.

Merchant joined Ernst's staff (as a graduate student in a unique post-graduate cooperative education programme at the University of Cincinnati) in 1936, having just graduated from the University of Vermont in Mechanical Engineering. Ernst asked him to undertake research on the mechanism of chip formation and, in particular, on the mechanism of the sliding friction between the chip and the cutting tool in chip formation.

As Merchant's friction research progressed (resulting, incidentally, in his theory of the nature of friction between chemically clean metal surfaces that is still in use today), he studied, considered and discussed with Ernst the latter's thoughts about chip formation and the empirical "shear plane" model. This led Merchant to reason that the chip could well be considered a body in stable mechanical equilibrium between the shear plane and the tool face. He therefore tried applying the science of the mechanics of solid bodies to such a concept. This resulted in the model of the equilibrium force system acting in the chip-tool-workpiece system shown in figure 1.

Combining ("condensing") the two equal and opposing sets of forces into one (based on the equality of the two opposing resultant forces), as shown in figure 2 , then made it possible to derive the mathematical relationships governing such forces, as set forth in Merchant's (1994) paper. The outcome was thus a science-based, predictive model of the basic process of chip formation - the first of its kind - and one which made possible engineering calculation of such quantities as the friction force acting between chip and tool, the coefficient of friction between them, shear stress at the shear plane etc. 


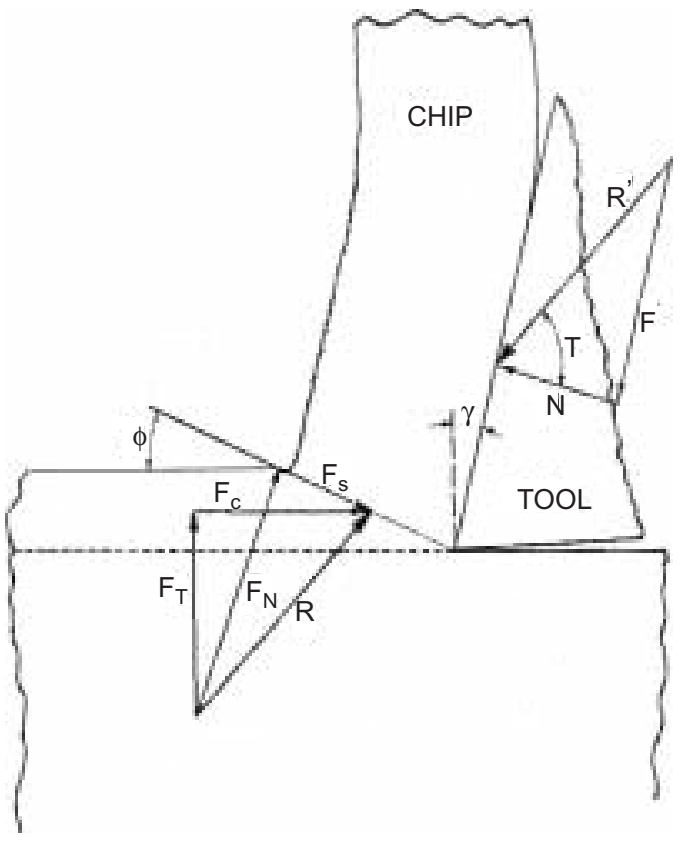

Figure 1. Equilibrium force system acting on chip during cutting (Merchant 1944).

From the circle diagram (figure 2), the following are obtained.

Chip ratio $=r_{c}=t_{1} / t_{2}=$ feed $/$ chip thickness.

Shear plane angle $=\tan \phi=r_{c} \sin \gamma / 1-r_{c} \cos \gamma$,

$$
\begin{aligned}
& F_{F}=F_{c} \sin \gamma+F_{t} \cos \gamma, \\
& F_{N}=F_{c} \cos \gamma-F_{t} \sin \gamma .
\end{aligned}
$$

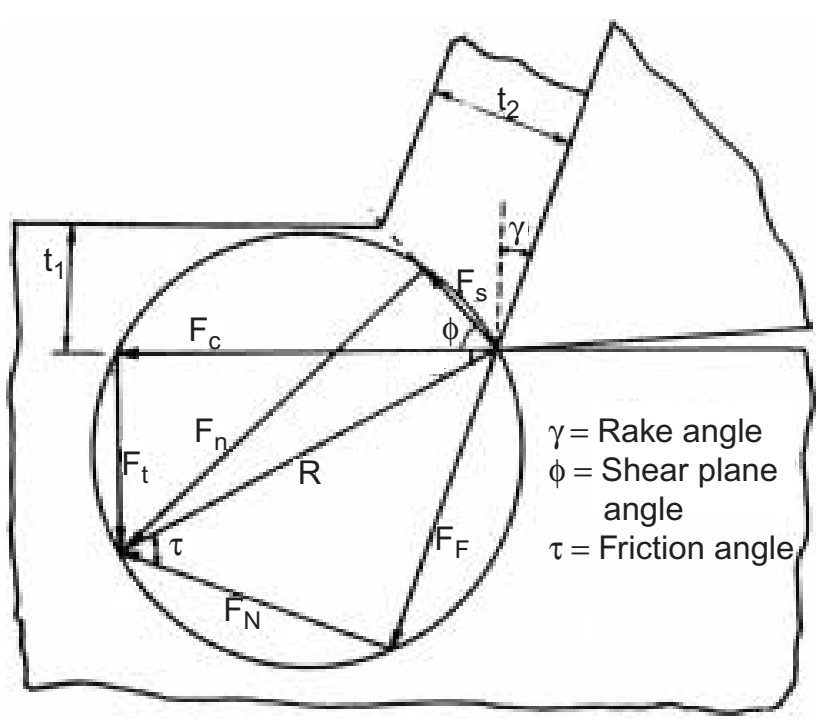

Figure 2. Condensed form of tool-chip-workpiece force system showing geometrical relationships between force components (Merchant 1944). 
Coefficient of friction $=\mu=\tan \tau=F_{F} / F_{N}$,

$$
F_{s}=R \cos (\phi+\tau-\gamma) \text {. }
$$

Shear stress $=t_{s}=F_{s} / A_{c}=F_{s} \sin \phi / A_{0}$.

Publication of this initial, basic model suddenly made it clear to those engaged in manufacturing research that a new approach to the modelling of the machining process was actually possible, namely that of science-based, predictive, modelling. This discovery thus ushered in a new era in metal cutting research, that which Komanduri (1993) has characterised as "the golden age of metal cutting and grinding research", lasting from about 1940 to 1960 . As a result, a worldwide effort to develop a substantial scientific basis for the modelling of the machining process gradually emerged, and then continued unabated through that whole period. In particular though, it was the academic community that responded, with research on science-based modelling of machining blossoming handsomely among manufacturing-oriented university researchers and faculty. During the period substantial progress in developing that science base was made, with a major part of that coming from the efforts of American engineering researchers and manufacturing engineers.

\section{Computer-based modelling}

Then, in the 1950s, a watershed event occurred that, in due time, added a whole new dimension to the technological modelling of machining operations. This was the advent of digital computer technology. This technology gave the first strong hint of its potential to make radical changes in the field of machining by its application to digital control of machine tools in the 1960s. Soon thereafter, it demonstrated powerful capability for simulation of processes, thus proving to be a potent tool for modelling the machining process. One of the most important strengths of this new modelling technology was its capability to combine both empirical and science-based models into its modelling capability. In addition, it proved able to simulate the actual ongoing performance of a machining operation; i.e. it could create "dynamic" models of such. However, of even broader significance was the fact that it provided powerful capability to integrate these dynamic models of machining performance with the performance of all of the rest of the overall system of machining, as first envisioned by Merchant (1961).

Accomplishment of such integration in industry (which was well along by early 1970s) enabled the process of performing simulation of machining operations to have full online access to all of the total database of the full system of manufacturing. Such capability greatly enhanced both the accuracy and the speed of computer-based modelling of machining operations.

One further and very important result of this integration of machining process models with the database of the full system of manufacturing was its enabling of the development of fully automated integrated systems of machine tools (which soon came to be known as "flexible manufacturing systems"). This advance enabled the machining process and its models to become far more productive than ever possible in the past.

\section{Today}

Today, the synergistic combination of the three types of modelling has resulted in the rapid development of modelling capability that considerably outstrips that which any one of the three 
The

Manufacturing System

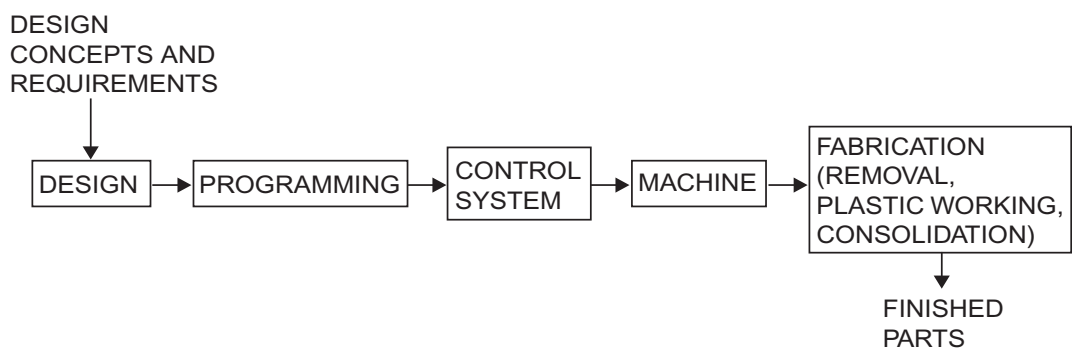

Figure 3. Initial concept of the computer integrated machining system as predicted in 1961 and which resulted in revolutionising manufacturing in the late sixties (Merchant 1961).

types would be capable of on its own. This is fortunate, however, since the rapid development of advanced manufacturing technology, based on digital computing technology, presents many new challenges to the practice of modelling of machining processes. These challenges take many forms. Just one example of such is the challenge posed by the fact that, in today's proliferating computer integrated manufacturing enterprises, machine tools are required to run ever more autonomously. Thus, they must become able to autonomously avoid or even correct processing errors or failures while machining is underway. Basic to advancement of such capability is significant increase in the accuracy and realism of machining process models. Accomplishment of this will require, among other things, increased utilisation of the fundamental knowledge, empirical or science-based, created by past research on the modelling of machining.

\section{List of symbols}

$A_{o} \quad$ uncut chip cross-sectional area;

$A_{C} \quad$ cut chip cross-sectional area;

$C$ an empirical constant incorporating the effect of all the cutting conditions (such as feed and depth of cut) on tool life;

$F_{F} \quad$ friction force on tool face;

$F_{N}$ normal force on tool face;

$F_{c} \quad$ cutting force on workpiece;

$F_{t} \quad$ thrust force on workpiece;

$F_{n} \quad$ normal force on shear plane;

$F_{s} \quad$ shear force on shear plane;

$n$ approximately $1 / 8$;

$R \quad$ resultant force on shear plane resultant force on chip face;

$T$ tool life (minutes or seconds);

$V \quad$ cutting time $(\mathrm{ft} / \mathrm{min}$ or $\mathrm{cm} / \mathrm{s})$;

$\alpha \quad$ rake angle of tool;

$\phi \quad$ shear angle;

$\tau \quad$ friction angle;

$\mu \quad$ coefficient of friction. 


\section{References}

Ernst H 1938 Machining of metals (Cleveland: American Society for Metals)

Komanduri R 1993 Machining and grinding: a historical review of the classical papers. Appl. Mech. Rev. 46: 80-132

Merchant M E 1944 Basic mechanics of the metal cutting process. J. Appl. Mech. Rev. A11: 168-175 Merchant M E 1961 The manufacturing system concept in production engineering research. Ann. CIRP 10: 77-83

Taylor F W 1906 On the art of cutting metals. Trans. Am. Soc. Mech. Eng. 28: 70-350 